\title{
EUFEMISME DAN DISFEMISME DALAM SPIEGEL ONLINE
}

\author{
Heti Kurniawati \\ Fakultas Sastra Universitas Negeri Malang \\ e-mail: heti_kurnia@yahoo.com
}

\begin{abstract}
This research aims to describe the forms of grammatical units of euphemisms and dysphemisms, and the backgrounds of euphemisms and dysphemisms uses in Spiegel Online. The data were collected through reading and note taking. The results show that the forms of grammatical units of euphemisms and dysphemisms in Spiegel Online consist of words, phrases and sentences. The backgrounds of the use of euphemisms in Spiegel Online are: 1) to avoid the use of words which can cause panic or anxiety; 2) to mitigate speech; 3 ) to diminish or tone down a painful evocation or tragedy; 4) to engage in diplomacy or rhetoric purposes; 5 ) to replace forbidden words, taboos, vulgar or negative imaged-words; 6) to hide something; 7) to respect or appreciate others; and 8) to tease or criticize others smoothly. The backgrounds of the use of dysphemisms in Spiegel Online are: 1) to constitute taboos, improper, or immoral matters; 2) to show one's dislike or disagreement; 3) to give negative description; 4) to show anger or irritation; 5) to scold; 6) to show disrespect; 7) to mock; 8) to exaggerate or overstate; 9) to criticize; and 10) to show trivial matters.
\end{abstract}

Keywords: euphemism, dysphemism, language style

\section{PENDAHULUAN}

Spiegel Online merupakan majalah Der Spiegel versi online, yang merupakan majalah umum yang memiliki pembaca paling banyak di Jerman, menonjol sebagai majalah politik dan memberikan dampak paling besar di antara publikasi mingguan untuk jangka panjang (Auswärtiges Amt, 2007: 172). Seperti media massa pada umumnya, Spiegel Online menggunakan bahasa yang tidak selalu apa adanya. Dijumpai juga penggunaan bahasa yang diperhalus atau diperindah. Sebagai contoh adalah kata Gotteskrieger yang menggantikan kata Terorrist (Zahn, 2004: 1). Gotteskrieger digunakan untuk menggantikan kata Terorrist yang memiliki kesan lebih buruk. Kata ini muncul setelah peristiwa penyerangan terhadap gedung World Trade Center pada 11 September 2001. Selain bahasa yang diperindah, Spiegel Online menggunakan bahasa yang diperkasar. Misalnya, "Köhlers Botschaft: Der Bundespräsident ist kein Unterschriftenautomat" (Presiden bukanlah mesin tanda tangan) (Malzahn, 2007: 1). Penyamaan orang atau manusia dengan benda merupakan hal yang tidak pantas. Presiden adalah orang yang berpikir, bukan hanya mesin yang hanya bisa menghasilkan tanda tangan. Gaya bahasa yang digunakan untuk memperhalus bahasa agar terkesan lebih indah bagi mitra tutur disebut eufemisme, sedangkan yang digunakan untuk memperkasar agar terkesan negatif bagi mitra tutur disebut disfemisme.

Eufemisme tidak selalu muncul dalam bentuk kata seperti contoh di atas, yakni Gotteskrieger. Ada kalanya eufemisme muncul dalam bentuk satuan gramatikal yang lebih besar. Contoh, 
er ist in die ewigen Jagdgründe eingegangen merupakan kalimat dan berarti 'ia telah memasuki medan perburuan yang abadi'. Kalimat tersebut merupakan penghalusan untuk menyatakan er ist gestorben, 'ia telah meninggal'.

Ditinjau dari latar belakang penggunaannya, eufemisme dan disfemisme memiliki berbagai latar belakang (Allan dan Burridge: 1991: 31). Misalnya, penggunaan Preisanpassung (penyesuaian harga) untuk menghaluskan kata Preiserhöhung (kenaikan harga) oleh pemerintah dimaksudkan untuk berdiplomasi agar tidak terjadi akses-akses yang tidak diinginkan. Contoh untuk disfemisme adalah, kata Scheiße (tahi) yang merupakan kata umpatan, digunakan untuk memaki atau mengumpat.

Menurut Keraf (2007: 132) eufemisme merupakan ungkapan-ungkapan yang tidak menyinggung perasaan orang, halus dan digunakan untuk menggantikan acuan-acuan yang mungkin dirasa menghina, menyinggung perasaan orang atau mensugestikan sesuatu yang tidak menyenangkan. " $\mathrm{A} \mathrm{eu-}$ phemism is used as an alternative to a dispreferred expression, in order to avoid possible loss of face: either one's own face or, through giving offensive, that of the audience, or of some third party" (Allan \& Burridge, 1991: 11). Eufemisme digunakan sebagai alternatif untuk ungkapan yang tidak disenangi, untuk menghindari kehilangan muka, baik muka sendiri maupun pendengar atau pihak ketiga dengan menyakiti.

Beberapa alasan mengapa eufemisme digunakan adalah sebagai berikut: (a) untuk menyatakan hal yang tabu, yang tidak mungkin untuk disebutkan secara langsung; (b) untuk menggantikan kata-kata yang dilarang. Dengan eufemisme, kata-kata tersebut memungkinkan untuk dipahami; (c) mencoba untuk menghindari penggunaan ungka- pan yang mengandung objek yang tabu, karena ungkapan berbahasa dapat dicemari oleh objek tabu tersebut (Schmidt, 2001: 1).

I Dewa Putu Wijana dan Muhammad Rohmadi (2008: 104-109) menyebutkan 5 (lima) alasan penggunaan eufemisme, yaitu: (a) untuk lebih menyenangkan, tidak menyinggung sehingga tidak menimbulkan konflik sosial; (b) sebagai alat untuk merahasiakan sesuatu, terutama digunakan dalam bidang kesehatan, misalnya penyakit kanker dan sipilis yang diganti dengan CA dan GO; (c) sebagai alat untuk berdiplomasi agar tidak menimbulkan akses-akses yang tidak diinginkan; (d) sebagai alat pendidikan, utamanya dilakukan orang tua kepada anaknya; dan (e) sebagai alat penolak bahaya, untuk memperoleh ketenangan atau keselamatan.

Wilpert (Zöllner, 1997: 92) memberikan beberapa alasan mengapa eufemisme digunakan yaitu: (a) untuk menghindari kata-kata atau hal-hal yang tabu; (b) untuk menutupi rasa malu; (c) untuk menghindari penggunaan kata-kata yang dapat menimbulkan bahaya; (d) untuk menunjukkan bahwa ia adalah orang yang berpendidikan; (e) karena alasan yang berkaitan dengan agama atau kepercayaan; (f) untuk menghindari penggunaan kata-kata yang terdengar kurang bagus; dan (g) untuk tujuan-tujuan retoris.

Menurut Brockhaus Enzyklopädie (Zöllner, 1997: 92-93), eufemisme digunakan untuk mengungkapkan hal-hal yang menyakitkan, menghina, atau menimbulkan rasa takut karena penghormatan yang sangat, untuk menghindari penggunaan kata-kata magis, Dalam bidang politik dan ekonomi, eufemisme digunakan dengan alasan untuk menutupi kenyataan atau untuk menghindari timbulnya kepanikan, misalnya Vertei- 
digungsfall (mempertahankan diri) untuk menggantikan Krieg (perang).

Disfemisme adalah "schlechte, $o b$ szöne Reden führen, Blasphemie betreiben" (ucapan atau kalimat yang jelek, cabul, menghujat) (Glück, 1993: 156). Disfemisme juga merupakan ungkapan yang bias, melukai atau menyinggung, mengungkapkan hal-hal yang tabu, menggunakan kata-kata umpatan atau makian (Schimpfwörter) dan kata-kata yang bersifat vulgar (Vulgarismen). "A dysphemism is an expression with connotations that are offensive either about the denotatum or to the audience, or both, and it is substituted for a neutral or euphemistic expression for just that reason" (Allan \& Burridge, 1991: 26). Disfemisme adalah ungkapan dengan konotasi yang menyakitkan, baik tentang pembicara maupun pendengar, atau keduanya, dan digantikan dengan ungkapan netral atau eufemisme karena alasan tersebut.

Disfemisme dapat berupa kalimat, seperti Der Bundespräsident ist kein Unterschriftenautomat" (Presiden bukanlah mesin tanda tangan). Akan tetapi, disfemisme dapat juga berupa kata, misalnya Drahtzieher. Secara harfiah, Drahtzieher berarti penarik benang dalam permainan marionet. Dalam konteks tertentu, Drahtzieher merupakan disfemisme untuk mengatakan Hintermann, orang yang berada dibalik suatu peristiwa. Drahtzieher selalu digunakan untuk merujuk kepada orang yang berada di balik suatu peristiwa buruk, misalnya terorisme.

"Wenn Wörter mit der Intention benutzt werden, jemanden zu kränken, Mißbilligung zu äußern oder etwas verächtlich zu machen, werden sie Dysphemismen" (Zöllner, 1997: 392). Jika kata digunakan dengan maksud untuk menyakiti seseorang, mengungkapkan penghinaan, atau merendahkan sesuatu, maka akan menjadi disfemisme. Disfemisme bertujuan untuk memberikan gambaran negatif tentang suatu tindakan atau seseorang. Berkaitan dengan katakata yang tabu, Wardhaugh (1990: 230) menyatakan bahwa penggunaan katakata yang tabu ntara lain untuk menarik perhatian kepada seseorang, menunjukkan rasa tidak hormat, menunjukkan sifat agresif atau provokatif, mengolokolok penguasa, atau pembujukan yang bersifat verbal.

Menurut Allan dan Burridge (1991: 27) disfemisme dapat digunakan antara lain untuk membicarakan tentang lawan, menunjukkan ketidaksepakatan seseorang, membicarakan tentang sesuatu yang dipandang sebagai sesuatu yang rendah, dan menghina seseorang. Zöllner (1997: 392-400) menguraikan beberapa alasan penggunaan disfemisme sebagai berikut: (a) untuk merendahkan atau mengungkapkan penghinaan; (b) untuk menunjukkan rasa tidak suka, juga ketidaksetujuan terhadap seseorang atau sesuatu; (c) untuk memperkuat atau mempertajam penghinaan; (d) untuk memberikan penggambaran yang negatif tentang lawan politik, baik pandangan, sikap, maupun prestasinya. (e) untuk mengungkapkan kemarahan dan kejengkelan; (f) untuk mengumpat atau menunjukkan kekuasaan.

Berdasarkan uraian di atas, eufemisme dan disfemisme dapat muncul dalam bentuk satuan gramatikal yang berbeda-beda. Latar belakang penggunaan eufemisme dan disfemisme pun berbeda-beda. Mengetahui satuan gramatikal eufemisme dan disfemisme menjadi penting untuk membantu pembaca memahami teks yang dibaca tersebut. Sementara itu, mengetahui latar belakang penggunaan kedua gaya bahasa tersebut akan membantu pembaca menerapkan atau menggunakan gaya bahasa tersebut dalam berkomunikasi, sesuai dengan konteks yang tepat. 


\section{METODE}

Jenis penelitian ini adalah penelitian analisis isi. Analisis isi adalah analisis yang digunakan untuk memahami pesan simbolik yang ada dalam dokumen, lukisan, tarian, lagu, karya sastra, dan lain-lain yang berupa data tak terstruktur (Darmiyati Zuchdi, 1993: 6). Penelitian ini termasuk analisis isi karena sumber datanya berupa dokumen, yakni teks berita. Langkah-langkah analisis isi mencakup empat tahapan. Tahapan pertama adalah pengadaan data yang meliputi penentuan satuan (unit), penentuan sampel, dan pencatatan. Tahapan selanjutnya adalah pengurangan atau reduksi data yang tidak diperlukan, analisis yang dapat dilakukan dengan analisis kuantitatif maupun kulitatif, dan inferensi atau penarikan kesimpulan (Darmiyati Zuchdi, 1993: 28).

Objek penelitian ini adalah eufemisme dan disfemisme yang digunakan dalam dalam Spiegel Online, sedangkan data dalam penelitian ini berupa satuan lingual dalam teks berita di Spiegel Online yang mengandung eufemisme dan disfemisme. Konteks data berupa kalimat bila datanya berupa kata atau frase, dan paragraf bila datanya berupa klausa. Konteks data menjadi sangat penting peranannya untuk mengklarifikasi makna eufemisme dan disfemisme, serta untuk mengungkapkan alasan penggunaannya kedua gaya bahasa tersebut. Sumber data pada penelitian ini adalah media Spiegel Online edisi November 2008. Rubrik yang digunakan sebagai sumber data adalah rubrik berita. Berita (Nachrichten) dalam Spiegel Online terdiri atas berita politik (Politik), ekonomi (Wirtschaft), panorama (Panorama), olahraga (Sport), budaya (Kultur), dunia internet atau komputer (Netzwelt), ilmu pengetahuan (Wissenschaft), perguruan tinggi (Unispiegel), sekolah (Schulspiegel), wisata (Reise), mobil (Auto). Berita yang dipilih sebagai sumber data adalah berita politik, ekonomi, panorama, olahraga, budaya, dan ilmu pengetahuan. Pemilihan tersebut didasarkan pada asumsi bahwa beritaberita tersebut lebih sering digunakan dalam pembelajaran bahasa Jerman.

Berita yang disajikan dalam Spiegel Online selalu diperbarui setiap harinya. Dengan demikian, dalam bulan November 2008, terdapat banyak sekali berita yang disajikan oleh Spiegel Online. Oleh karena itu, berita dibatasi sebanyak dua edisi per minggu, yang mewakili awal pekan (Senin) dan akhir pekan (Sabtu). Pembagian tersebut berdasarkan asumsi bahwa berita yang disajikan pada waktu tersebut berbeda, yakni pada edisi akhir pekan berita yang disajikan cenderung lebih santai. Berita yang disajikan dalam satu hari pun tidak hanya sebuah berita saja. Oleh karena itu, berita yang menjadi sumber data adalah berita yang memiliki judul paling besar dan atau berada paling atas. Berita tersebut dianggap berita yang paling penting atau terbaru.

Berdasarkan pertimbangan di atas, maka berita dalam Spiegel Online yang menjadi sumber data sebanyak 9 (sembilan) edisi, yakni edisi tanggal 1 , $3,8,10,15,17,22$, 24, dan 29 November 2008. Masing-masing edisi terdiri atas 6 (enam) teks berita, yakni berita politik, ekonomi, panorama, olahraga, budaya, dan ilmu pengetahuan. Jumlah keseluruhan berita yang menjadi sumber data adalah 54 teks berita.

Teknik pengumpulan data yang digunakan dalam penelitian ini adalah teknik simak dan catat. Menurut Mahsun (2005: 92) metode simak digunakan untuk memperoleh data yang dilakukan dengan menyimak. Istilah menyimak di sini tidak hanya berkaitan dengan penggunaan bahasa secara lisan, tetapi juga penggunaan bahasa secara tertulis. Simak dalam konteks penelitian ini 
berarti membaca. Peneliti membaca dengan seksama berita dalam Spiegel Online untuk menentukan bentuk satuan gramatikal eufemisme dan disfemisme serta latar belakang penggunaan eufemisme dan disfemisme. Data dikumpulkan beserta konteksnya. Konteks ini diperlukan guna mengklarifikasikan makna eufemisme dan disfemisme, serta latar belakang penggunaannya. Di dalam kegiatan pembacaan dilakukan kegiatan pencatatan untuk mendokumentasikan data yang diperoleh. Data yang diperoleh kemudian dicatat dalam kartu data.

Instrumen penelitian dalam penelitian ini adalah peneliti sendiri (human instrument). Pengetahuan peneliti tentang bahasa Jerman, terutama yang berkaitan dengan gaya bahasa eufemisme dan disfemisme menjadi sangat penting. Selain itu, pengetahuan tentang kebudayaan Jerman merupakan hal yang juga penting. Peneliti adalah seorang dosen bahasa Jerman dan dianggap memiliki pengetahuan tentang bahasa dan budaya Jerman.

Dalam mengumpulkan data, peneliti dibantu oleh perangkat lunak yang berupa kriteria-kriteria. Kriteria-kriteria ini merupakan kriteria untuk menentukan satuan gramatikal eufemisme dan disfemisme, serta faktor-faktor yang melatarbelakangi penggunaan eufemisme dan disfemisme, seperti yang dijabarkan dalam kajian teori. Hasil pengamatan terhadap sumber data kemudian dicatat dalam kartu data sebagai perangkat kerasnya. Kartu data ini berfungsi untuk mencatat dan mengidentifikasikan bentuk satuan gramatikal eufemisme dan disfemisme serta latar belakang penggunaannya.

Keabsahan data penelitian ini diperoleh dengan memenuhi kriteria kredibilitas, yaitu kriteria untuk memenuhi kebenaran dari data dan infor- masi yang dikumpulkan (Syamsuddin AR \& Vismaia S. Damaianti, 2007: 91). Kriteria kredibilitas diperoleh dengan intrarater dan interater. Intrarater dipenuhi dengan pengamatan yang terusmenerus dan berulang-ulang, agar semua data terjaring. Interater dilakukan dengan diskusi teman sejawat, yakni diskusi dengan seorang dosen Sastra Jerman, Fakultas Sastra, UM, yaitu Edy Hidayat, S.Pd. M.Hum. Selain itu, juga dilakukan triangulasi dengan penutur asli bahasa Jerman, yaitu dengan Astrid Raabe, M.A. yang merupakan Lektor DAAD yang sedang bertugas di Universitas Negeri Malang.

Teknik analisis data yang digunakan adalah teknik padan. Teknik padan merupakan teknik analisis yang alat penentunya berada di luar bahasa dan tidak menjadi bagian dari bahasa itu sendiri (Sudaryanto, 2001: 13). Selanjutnya teknik padan yang digunakan adalah teknik padan referensial untuk mengetahui satuan gramatikal eufemisme dan disfemisme. Teknik padan referensial dengan pendekatan semantik digunakan untuk mengetahui makna eufemisme dan disfemisme. Sementara itu, untuk menganalisis latar belakang penggunaan eufemisme dan disfemisme digunakan analisis padan pragmatik.

Hasil penelitian disajikan dengan menggunakan metode informal. Metode informal adalah menggunakan katakata biasa, termasuk penggunaan terminologi yang bersifat teknis (Mahsun, 2005: 123). Penyajian data tidak menggunakan notasi khusus.

\section{HASIL PENELITIAN DAN PEMBA- HASAN \\ Eufemisme dalam Spiegel Online}

Ditinjau dari bentuk satuan gramatikal, eufemisme yang digunakan dalam Spiegel Online terdiri atas satuan gramatikal kata, frasa, dan kalimat. 
Ditinjau dari latar belakang ditemukan

8 alasan penggunaan eufemisme dalam Spiegel Online.

Tabel 1 Eufemisme dalam Spiegel Online

\begin{tabular}{|c|c|c|c|c|c|c|c|c|c|c|c|}
\hline \multirow[b]{2}{*}{ No. } & \multirow{2}{*}{\multicolumn{2}{|c|}{$\begin{array}{c}\text { Bentuk Satuan } \\
\text { Gramatikal } \\
\text { Eufemisme }\end{array}$}} & \multicolumn{8}{|c|}{ Latar Belakang Penggunaan } & \multirow[b]{2}{*}{ Jumlah } \\
\hline & & & 1 & 2 & 3 & 4 & 5 & 6 & 7 & 8 & \\
\hline \multirow{2}{*}{1} & \multirow{2}{*}{ Kata } & Tunggal & 5 & 2 & - & - & 1 & - & 1 & - & 9 \\
\hline & & Majemuk & - & - & 2 & - & 1 & 2 & - & 3 & 8 \\
\hline 2 & Frasa & & 2 & 9 & 5 & 4 & 1 & 3 & - & - & 24 \\
\hline \multirow[t]{2}{*}{3} & \multirow{2}{*}{\multicolumn{2}{|c|}{$\begin{array}{l}\text { Kalimat } \\
\text { Jumlah Total }\end{array}$}} & 1 & 6 & - & 4 & - & 4 & - & 2 & 17 \\
\hline & & & 8 & 17 & 7 & 8 & 3 & 9 & 1 & 5 & 58 \\
\hline
\end{tabular}

Keterangan:

Latar belakang penggunaan:

1. menghindari penggunaan kata-kata yang dapat menimbulkan kepanikan atau ketakutan;

2. tidak menyinggung, menghina, atau merendahkan seseorang;

3. mengurangi atau tidak menyinggung hal-hal yang menyakitkan atau tragedi;

4. berdiplomasi atau bertujuan retoris;

5. menggantikan kata-kata yang dilarang, tabu, vulgar atau bercitra negatif;

6. merahasiakan sesuatu;

7. menghormati atau menghargai orang lain;

8. menyindir atau mengkritik.

Ditinjau dari bentuknya, satuan gramatikal eufemisme dalam Spiegel Online terdiri atas tiga bentuk, yaitu kata, frasa, dan kalimat. Kata adalah satuan gramatikal terkecil yang bebas dan memiliki makna. Kata dapat berupa kata dasar, kata berimbuhan, maupun kata majemuk (Komposita).

(1)Es wurde ihm vom Gericht auch untersagt, Kontakt zu Osama bin Laden aufzunehmen, als dessen "Botschafter" in Europa Abu Qatada gilt. (050/Kul/01/11/08) (Pengadilan melarangnya berhubungan dengan Osama bin Laden, karena Abu Qatada adalah "duta besar"nya di Eropa.)

Pada kalimat (1) Botschafter merupakan kata berimbuhan yang berasal dari kata benda Bote (tukang antar surat), mendapat akhiran -schaft, dan -er sehingga menjadi Botschafter (duta besar). Jika berdiri sendiri, kata Botschafter memiliki makna duta besar, yakni perwakilan suatu negara di negara lain dan bukan merupakan penghalusan atau eufemisme. Botschafter digunakan untuk menggantikan kata Handlanger atau Komplize (kaki tangan, anak buah, atau komplotan).

Frasa adalah kelompok kata yang terdiri atas dua kata atau lebih dan memiliki satu kepala atau inti. Frasa tidak memiliki fungsi predikatif dan tidak bermakna proposisi, hanya merupakan istilah. Frasa juga tidak memiliki kata kerja finit.

(2) Denn dass die Reiter ihre Pferde mit vielerlei unerlaubten Hilfsmitteln präparieren, damit diese am Wettkampftag Höchstleistung bringen, steht mittlerweile außer Frage. (022/Spo/01/11/08) (Bahwa para joki mempersiapkan kuda-kuda mereka dengan bermacam-macam alat bantu yang tidak diijinkan, agar mendapatkan prestasi terbaik pada pertandingan hari ini, sampai saat ini sudah diketahui dengan pasti.) 
Kelompok kata unerlaubtes Hilfsmittel (alat bantu yang tidak diijinkan) merupakan frasa dan bukan kalimat karena kelompok kata tersebut hanya memiliki satu kepala, tidak memiliki kata kerja finit dan tidak memiliki fungsi predikatif. Kepala dalam kelompok kata tersebut adalah kata Hilfsmittel, yang merupakan kata benda, sedangkan unerlaubt hanya atribut menerangkan Hilfsmittel.

Kalimat adalah kumpulan atau rangkaian kata yang memiliki kata kerja finit atau final, yakni kata kerja yang sudah mengalami perubahan karena menyesuaikan dengan persona dan numeranya.

(3) Steinbrück hat nach eigenen Worten inzwischen "einen dicken Hals". (009/Wir/01/11/08)

(Steinbrück marah dengan bahasanya sendiri.)

Kelompok kata Steinbrück hat einen dicken Hals (Steinbrück marah) memiliki unsur kalimat subjek (S), yaitu Steinbrück, dan predikat (P) yaitu hat einen dicken Hals. Selain itu, terdapat juga kata kerja finit, yaitu hat, yang berasal dari kata kerja infinitif haben dan melekat pada subjek orang ketiga tunggal, Steinbrück.

Seperti sudah diuraikan di depan, penggunaan eufemisme dalam Spiegel Online ditafsirkan untuk hal-hal sebagai berikut.

Pertama, eufemisme ditafsirkan untuk menghindari penggunaan katakata yang dapat menimbulkan kepanikan atau ketakutan

(4) Und Azam Amir Kasav hat gekämpft. (213/Pol/21/11/08)

(Dan Azam Amir Kasav telah berjuang.)

Azam Amir Kasav hat gekämpft merupakan penghalusan dari Asam Amir Kasav hat einen Terroranschlag verübt (Azam Amir Kasav telah melakukan serangan teror). Seperti diketahui, Azam
Amir Kasav adalah seorang pelaku pemboman di Mumbai, India dan dianggap sebagai seorang teroris yang melakukan pembunuhan massal. Segala hal yang berhubungan dengan dengan teror dan teroris selalu menimbulkan ketakutan dan kecemasan dalam masyarakat karena menyangkut keamanan hidup masyarakat.

Kedua, eufemisme ditafsirkan untuk memperhalus ucapan agar tidak menyinggung, menghina, atau merendahkan seseorang

(5) Ypsilanti ging auf die Auseinandersetzung in ihrer Rede am heutigen Samstag ein. Sie hätte sich gewünscht, dass er der Regierung angehöre, sagte sie. Ihm war zuletzt das Ressort für Verkehr und Europa angeboten worden. Walter habe aber für sich entschieden, dass der Zuschnitt des Ministeriums nicht seinen Vorstellungen entspreche. (003/ $\mathrm{Pol} / 01 / 11 / 08)$

(Ypsilanti memahami pertengkaran dalam pidatonya pada sabtu ini. Saya berharap Walter menjadi bagian dari pemerintah, katanya. Pada akhirnya Walter ditawari Departemen Perhubungan dan Eropa. Tetapi Walter memutuskan, bahwa bentuk kementerian itu tidak cocok dengan pemikiran-pemikirannya.)

Ypsilanti merupakan calon kuat dari SPD untuk menjadi Ministerpresidentin (Prime Minister atau Perdana Menteri) di negara bagian Hessen. Walter yang semula mendukungnya, pada akhirnya berbalik tidak mau mendukungnya. Ypsilanti menawarkan satu posisi kepada Walter sebagai menteri di Departemen Perhubungan dan Eropa, agar Walter kembali mendukungnya, tetapi Walter menolak.

Ketiga, eufemisme ditafsirkan untuk mengurangi atau tidak menyinggung hal-hal yang menyakitkan atau tragedi 
(6) Deswegen war in den Ländern des real existierenden Sozialismus der "Frieden" das wichtigste aller Ziele, nicht die "Freiheit". (055/Kul/01/11/08)

(Oleh karena itu, di negaranegara yang dulu pernah ada paham sosialis, kedamaian adalah tujuan utama, bukan kebebasan.)

Frasadie Länder des real existierenden Sozialismus (negara-negara yang dulu pernah ada paham sosialis) merupakan penghalusan dari Ostblock (Blok Timur), sebutan untuk negara Uni Soviet dan sekutu-sekutunya yang menganut paham sosialis. Penyebutan Ostblock secara langsung akan mengingatkan orang kepada perang dingin yang telah membawa penderitaan bagi masyarakat Jerman. Salah satu dampak dari perang dingin tersebut adalah pemisahan Jerman menjadi dua bagian, Jerman Barat dan Jerman Timur. Pemisahan tersebut menyebabkan banyak penderitaan bagi rakyat Jerman, terutama Jerman Timur yang berada di bawah kekuasaan Blok Timur yang dipimpin oleh Uni Soviet.

Keempat, eufemisme ditafsirkan untuk berdiplomasi atau bertujuan retoris

(7) Die Betriebe schränken ihre Produktion ein und reduzieren die Zahl ihrer Beschäftigten. (188/Wir/24/11/08)

(Pabrik-pabrik membatasi produksi dan mengurangi jumlah pekerja mereka.)

Die Betriebe reduzieren die Zahl ihrer Beschäftigten (pabrik-pabrik mengurangi jumlah karyawan) merupakan penghalusan dari die Betriebe entlassen ihre Beschäftigten (pabrik-pabrik memecat karyawannya). Terkait dengan krisis ekonomi yang melanda seluruh negara, termasuk Jerman, banyak perusahaan yang mengalami kebangkrutan dan terpaksa harus mengurangi jumlah pekerjanya. Untuk keperluan diplomasi agar tidak terjadi gejolak atau kegelisahan di masyarakat, maka digunakan kalimat yang lebih halus untuk mengungkapkan pemecatan yang dilakukan oleh perusahaan. Die Betriebe reduzieren die Zahl ihrer Beschäftigten terdengar lebih halus atau lebih enak daripada die Betriebe entlassen ihre Beschäftigten.

Kelima, eufemisme ditafsirkan untuk menggantikan kata-kata yang dilarang, tabu, vulgar atau bercitra negatif

(8) Es wurde ihm vom Gericht auch untersagt, Kontakt zu Osama bin Laden aufzunehmen, als dessen "Botschafter" in Europa Abu Qatada gilt. (050/Kul/01/11/08) (Pengadilan melarangnya berhubungan dengan Osama bin Laden, karena Abu Qatada adalah "duta besar"nya di Eropa.)

Kata Botschafter (duta besar) merupakan bentuk penghalusan untuk menggantikan kata Handlanger (anak buah) atau Komplize (komplotan). Dalam kalimat (11), penggunaan kata Botschafter adalah untuk menghindari penggunaan kata Handlanger yang memiliki makna yang lebih rendah. Abu Qatada merupakan anak buah dari Osama bin Laden yang dianggap sebagai teroris internasional. Itu berarti Abu Qatada juga dianggap sebagai seorang teroris. Di dalam masyarakat, teroris memiliki citra yang sangat buruk, karena mengancam kehidupan mereka.

Keenam, eufemisme ditafsirkan untuk merahasiakan sesuatu

(9) Nach Schätungen kämpft jeder 20. der über 63-jährigen Deutschen mit einer Posttraumatischen Belastungsstörung. (060/ Wis/01/11/08)

(Diperkirakan seperduapuluh dari orang Jerman yang berusia di atas 63 tahun hidup dengan penyakit tekanan jiwa pasca trauma.)

Posttraumatische Belastungsstörung atau PTBS adalah gejala psikis dan psikosomatis yang merupakan efek jangka 
panjang dari adanya trauma. Frasa ini merupakan istilah khusus dalam bidang psikologi dan tidak semua orang mengetahui penyakit yang sebenarnya. Penggunaan istilah khusus ini dimaksudkan untuk menyembunyikan hal tentang penyakit yang diderita oleh si pasien, yakni depresi dengan masalah psikis.

Ketujuh, eufemisme ditafsirkan untuk menghormati orang lain

(10) Ein Viertel dieser Kinder wuchs ohne Vater auf, weil der gefallen oder in Kriegsgefangenschaft war. (061/Wis/01/11/08)

(Seperempat anak-anak ini tumbuh tanpa ayah, karena ayahnya gugur atau dipenjara.)

Kata fallen (jatuh) digunakan untuk memperhalus kata sterben (mati). Kata ini digunakan untuk menghaluskan sterben, tetapi hanya khusus digunakan bagi para pahlawan atau orang yang meninggal di medan perang. Kata fallen digunakan untuk memberikan penghormatan bagi pahlawan dan orang-orang yang gugur di medan perang.

Kedelapan, eufemisme ditafsirkan untuk menyindir atau mengkritik dengan halus

(11)Nun aber sollen die Regeln des Verbands "wirkungsvol- ler" durchgesetzt werden, etwa mit mehr Kontrollen. (028/ Spo/01/11/08)

(Seharusnya peraturan perkumpulan itu dilaksanakan lebih efisien, dengan pengawasan yang lebih.)

Kata wirkungsvoller (lebih efisien) dalam kalimat di atas merupakan bentuk eufemistis untuk stärker (lebih keras). Dalam konteks di atas, kata wirkungsvoller digunakan untuk mengkritik organisasi olah raga berkuda Jerman. Kritik itu disampaikan untuk mengkritisi peraturan yang dibuat oleh organisasi tersebut. Peraturan yang diberlakukan dianggap masih belum efektif, terbukti dengan masih banyaknya atlet berkuda yang menggunakan doping atau alatalat bantu ilegal untuk meraih kemenangan.

\section{Disfemisme dalam Spiegel Online}

Ditinjau dari bentuk satuan gramatikal, disfemisme yang digunakan dalam Spiegel Online berupa satuan gramatikal kata, frasa, dan kalimat. Ditinjau dari latar belakang penggunaannya, penggunaan disfemisme dalam Spiegel Online ditafsirkan memiliki 10 alasan.

Tabel 2 Disfemisme dalam Spiegel Online

\begin{tabular}{|c|c|c|c|c|c|c|c|c|c|c|c|c|c|}
\hline \multirow{2}{*}{ No. } & \multirow{2}{*}{\multicolumn{2}{|c|}{$\begin{array}{c}\text { Bentuk Satuan } \\
\text { Gramatikal } \\
\text { Disfemisme }\end{array}$}} & \multicolumn{10}{|c|}{ Latar Belakang Penggunaan } & \multirow{2}{*}{ Jumlah } \\
\hline & & & 1 & 2 & 3 & 4 & 5 & 6 & 7 & 8 & 9 & 10 & \\
\hline \multirow{2}{*}{1} & \multirow{2}{*}{ Kata } & Tunggal & 1 & - & 55 & 7 & 1 & 21 & 6 & 10 & 1 & 2 & 104 \\
\hline & & Majemuk & 2 & 1 & 19 & 3 & - & 5 & 14 & 4 & 2 & 2 & 52 \\
\hline 2 & \multicolumn{2}{|l|}{ Frasa } & - & - & 3 & - & - & 1 & 10 & - & 4 & - & 18 \\
\hline 3 & \multicolumn{2}{|c|}{ Kalimat } & - & - & - & 1 & - & 1 & 2 & 1 & - & - & 5 \\
\hline \multicolumn{3}{|c|}{ Jumlah Total } & 3 & 1 & 77 & 11 & 1 & 28 & 32 & 15 & 7 & 4 & 179 \\
\hline
\end{tabular}


Keterangan:

Latar belakang penggunaan:

1. menyatakan hal yang tabu, tidak senonoh, asusila;

2. menunjukkan rasa tidak suka atau tidak setuju terhadap seseorang atau sesuatu;

3. penggambaran yang negatif tentang seseorang atau sesuatu;

4. mengungkapkan kemarahan atau kejengkelan;

5. mengumpat atau memaki;

6. menunjukkan rasa tidak hormat atau merendahkan seseorang;

7. mengolok-olok, mencela, atau menghina;

8. melebih-lebihkan sesuatu;

9. menghujat atau mengkritik;

10. menunjukkan sesuatu hal yang bernilai rendah.

Berdasarkan bentunya, satuan gramatikal disfemisme dalam Spiegel Online yang ditemukan sebanyak 179 data, dan terbagi menjadi satuan gramatikal kata, frasa, dan kalimat.

(12)Vor allem Steinbrück wird dafür kritisiert, dass die Banken das Geld der Steuerzahler verschmähen. (008/Wir/01/11/08)

(Terutama Steinbrück dikritik, bank-bank menolak uang para pembayar pajak.)

Kata verschmähen (menolak dengan angkuh), yang merupakan kata kerja. Dalam kalimat (4) kata verschmähen telah mengalami proses morfologis, yakni konjugasi, perubahan bentuk akibat penyesuaian terhadap subjeknya.

(13) “O-a-sis! O-a-sis!" brüllt alles, und wer sich je gefragt haben sollte, warum die Band nur auf diesen dämlichen Namen kommen konnte, weiß es heute: Man kann ihn wahnsinnig gut betrunken skandieren. (101/Kul/08/11/08) ("O-a-sis! O-a-sis!" semua berteriak, dan siapa yang pernah bertanya, mengapa band ini bisa diberi nama bodoh ini, sekarang ia tahu: orang bisa meneriakkan nama itu sambil mabuk.)

Kelompok kata dämmlicher Name (nama yang bodoh) hanya merupakan frasa, bukan sebuah kalimat karena tidak memiliki kata kerja finit dan fungsi predikatif. Kepala dari kelompok kata di atas adalah kata Name. Kata dämmlich yang merupakan kata sifat hanya merupakan atribut bagi kata Name yang merupakan kata benda.

(14)Der Markt reagiere erleichtert, dass "keine Bombe geplatzt" sei. (112/Wir/10/11/08)

(Pasar bereaksi meringankan, bahwa tidak ada bom yang dipasang.)

Keine Bombe ist geplatzt (tidak ada bom yang dipasang) memiliki subjek (S) keine Bombe dan predikat (P) ist geplatzt. Kata ist merupakan kata kerja finit dari sein yang melekat pada subjek orang ketiga tunggal, yaitu keine Bombe. Karena memiliki unsur predikatif, maka keine Bombe ist geplatzt merupakan kalimat dan dalam kalimat (6) menduduki jabatan sebagai anak kalimat, yang dihubungkan oleh penghubung dass (bahwa).

Ditinjau dari latar belakang penggunaannya, disfemisme dalam Spiegel Online digunakan untuk alasan sebagai berikut.

Pertama, disfemisme ditafsirkan untuk menyatakan hal yang tabu, tidak senonoh, atau asusila

(15)Die Boni-Affäre bei der Bundesbahn wird Wolfgang Tiefensee immer mehr zum Verhängnis. (070/Wir/03/11/08)

(Skandal bonus pada perkeretaapian semakin mendekatkan Wolfgang Tiefensee ke penjara.)

Boni-Affäre (skandal bonus) di perkeretaapian Jerman, seperti halnya skandal yang lain juga merupakan sesuatu yang bercitra negatif di 
masyarakat. Makna yang lebih netral atau halus untuk Boni-Affäre adalah Boni-Problem (masalah bonus).

Kedua, disfemisme ditafsirkan untuk menunjukkan rasa tidak suka, tidak setuju terhadap seseorang atau sesuatu

(15)“... Ohne Menschen gäbe es auch keine Kriege mehr und keine Massenvernichtungswaffen, die alles Leben bedrohen. ..." (042/ $\mathrm{Kul} / 01 / 11 / 08)$

(“... Tanpa manusia maka tak akan ada lagi perang dan tidak ada senjata pemusnah masal yang mengancam kehidupan semuanya....")

Massenvernichtungswaffen adalah senjata pemusnah massal dan merupakan bentuk disfemisme dari atomare, biologische, chemische Waffen (senjata atom, biologis, dan kimia) atau lebih sering disingkat $A B C$-Waffen (senjata $\mathrm{ABC}$ ). Dengan penggunaan disfemisme di atas, Dalai Lama hendak menyampaikan ketidaksukaan atau ketidaksetujuan terhadap penggunaan senjata pemusnah massal tersebut, yang dapat mengancam kehidupan semua makhluk di bumi ini.

Ketiga, disfemisme ditafsirkan untuk memberikan penggambaran negatif tentang seseoran

(16)Auch ein mutmaßlicher TopGangster ging den Ermittlern ins Netz. (086/Pan/08/11/08)

(Penyidik mengirim seorang tersangka penjahat nomor satu ke penjara.)

Top-Gangster (penjahat nomor satu) sudah memiliki citra yang tidak baik di masyarakat. Penggunaan kata Top-Gangster merupakan penggambaran yang lebih negatif dari Hauptverbrecher (penjahat utama) dan semakin mempertegas citra penjahat yang negatif dan pantas masuk penjara.

Keempat, disfemisme ditafsirkan untuk mengungkapkan kemarahan atau kejengkelan

(17) “Lasst uns nicht vergessen, dass die Paparazzi Prinzessin Diana umgebracht haben. ..." (147/ Pan/17/11/08)

("Jangan kita lupa, bahwa paparazzi telah memb unuh Putri Diana. ...")

Kata papparazi (reporter dan fotografer skandal orang-orang terkenal) memang sudah memiliki citra negatif di masyarakat. Penggunaan kata paparazzi dimaksudkan untuk menunjukkan kekesalan seseorang (Kanye West) terhadap paparazzi. Kanye West terlibat pertikaian dengan paparazzi yang terus mengikuti dan hendak mengambil gambarnya.

Kelima, disfemisme ditafsirkan untuk mengumpat atau memaki

(18)Als ich wusste, dass ich Formel 1 fahre und hörte, dass er aufhört, dachte ich: Scheiße. (079/ Spo/03/11/08)

(Ketika saya tahu bahwa saya bertanding di Formula 1 dan dia berhenti, saya pikir: sialan.)

Scheiße (tahi) adalah kata umpatan yang sering digunakan di masyarakat Jerman. Oleh karena itu, penggunaan kata umpatan (Schimpfwort) dalam konteks di atas dimaksudkan untuk mengumpat.

Keenam, disfemisme ditafsirkan untuk menunjukkan rasa tidak hormat atau merendahkan seseorang

(19)Auch der Komplize von Kasav wurde bei der Schießerei getötet, eine Kugel traf Kasav in die Hand. (217/Pol/29/11/08)

(Bahkan teman Kasav terbunuh dalam penembakan itu, sebuah peluru mengenai tangan Kasav.)

Penggunaan kata Komplize (teman) sebagai pengganti Freund (teman) dalam konteks di atas merupakan suatu bentuk tidak menghormat kepada Kasav. Rasa tidak hormat tersebut disebabkan karena Kasav adalah salah satu teroris yang telah melakukan aksi penyerangan di Mumbai beberapa wak- 
tu yang lalu. Oleh karena itu, Kasav bukanlah seseorang yang perlu dihormati, demikian pula dengan temannya.

Ketujuh, disfemisme ditafsirkan untuk mengolok-olok, mencela, menghina

(20)Hessen-Wahlkämpfer Koch gibt den Job-Garanten, CDU-Chefin Merkel die Krisenkanzlerin, ihr SPD-Vize Steinmeier schart Betriebsräte um sich. (134/ $\mathrm{Pol} / 17 / 11 / 08)$

(Peserta pemilu dari Hessen, Koch memberikan garansi pekerjaan, ketua CDU Merkel kanselir krisis, wakilnya dari SPD, Steinmeier mendekati dewan-dewan perusahaan.)

Krisenkanzlerin (kanselir krisis) dalam konteks di atas yang digunakan untuk menyebut Angela Merkel merupakan suatu bentuk olok-olok atau hinaan terhadap Merkel. Merkel adalah kanselir Jerman. Penambahan penyebutan menjadi Krisenkanzlerin dikarenakan pada masa jabatannya, Jerman mengalami masa krisis keuangan dan perekonomian.

Kedelapan, disfemisme ditafsirkan untuk melebih-lebihkan sesuatu

(21)Was passieren würde, wenn die Banken Staatshilfen weiter verschmähen, sagte er nicht. (010/ Wir/01/11/08)

(Apa yang akan terjadi jika bank-bank menolak bantuan pemerintah,iatakmengatakannya.)

Penggunaan kata verschmähen (menolak dengan angkuh) dalam kalimat di atas menunjukkan bahwa penulis ingin mengungkapkan penolakan yang sangat kuat atas bantuan pemerintah. Oleh karena itu, penggunaan kata verschmähen dirasa lebih memiliki kesan yang bombastis di masyarakat daripada ablehnen.

Kesembilan, disfemisme ditafsirkan untuk menghujat atau mengkritik

(22)Eigentlich hatten die Skeptiker damit gerechnet, dass Moskaus schamlose Kopie der US-Technik in einem Feuerball verglühen würde. (132/Wis/15/11/08)

(Sebenarnya orang-orang yang skeptis juga mengharapkan, bahwa Moskow akan menghentikan penjiplakan tanpa malu terhadap teknik AS tentang sebuah bola api.)

Schamlose Kopie merupakan frasa disfemistis yang berarti penjiplakan tanpa malu. Frasa disfemistis ini digunakan untuk mengkritik negara Rusia yang telah menjiplak teknik Amerika Serikat. Pemerintah Rusia dinilai tidak tahu malu karena telah menjiplak teknik yang dimiliki oleh Amerika Serikat.

Kesepuluh, disfemisme ditafsirkan untuk menunjukkan sesuatu hal yang bernilai rendah

(23)Damit dort nichts schiefgeht, hat die FN ein System eingeführt, das an das Dopingsystem der DDR erinnert. (027/Spo/01/11/08)

(Peristiwa itu mengingatkan pada sistem doping di DDR/ Jerman Timur.)

Seperti diketahui, banyak atlet dari Jerman Timur yang menggunakan doping pada saat pertandingan olahraga. Penggunaan kata Dopingsystem dalam konteks di atas yang dihubungkan dengan Jerman Timur semakin menunjukkan bahwa sistem doping yang pernah terjadi di Jerman Timur merupakan sesuatu yang bernilai rendah dan telah mencemari nama baik olahraga di Jerman.

\section{SIMPULAN}

Berdasarkan uraian di atas, dapat disimpulkan bahwa bentuk satuan gramatikal eufemisme dalam Spiegel Online adalah kata, frasa, dan kalimat. Eufemisme yang paling banyak muncul berupa satuan gramatikal frasa. Bentuk satuan gramatikal disfemisme dalam Spiegel Online berupa kata, frasa, dan ka- 
limat. Disfemisme yang paling banyak muncul dalam Spiegel Online berupa satuan gramatikal kata.

Latar belakang penggunaan eufemisme dalam Spiegel Online ditafsirkan untuk: (1) menghindari penggunaan kata-kata yang dapat menimbulkan kepanikan atau ketakutan; (2) tidak menyinggung, menghina, atau merendahkan seseorang; (3) mengurangi atau tidak menyinggung hal-hal yang menyakitkan atau tragedi; (4) berdiplomasi atau bertujuan retoris; (5) menggantikan kata-kata yang dilarang, tabu, vulgar atau bercitra negatif; (6) merahasiakan sesuatu; (7) menghormati atau menghargai orang lain; (8) menyindir atau mengkritik dengan halus. Sementara itu, latar belakang penggunaan disfemisme dalam Spiegel Online ditafsirkan untuk: (1) menyatakan hal yang tabu, tidak senonoh, asusila; (2) menunjukkan rasa tidak suka atau tidak setuju terhadap seseorang atau sesuatu; (3) penggambaran yang negatif tentang seseorang atau sesuatu; (4) mengungkapkan kemarahan atau kejengkelan; (5) mengumpat atau memaki; (6) menunjukkan rasa tidak hormat atau merendahkan seseorang; (7) mengolok-olok, mencela, atau menghina; (8) melebih-lebihkan sesuatu; (9) menghujat atau mengkritik; (10) menunjukkan sesuatu hal yang bernilai rendah.

\section{UCAPAN TERIMAKASIH}

Artikel ini diangkat dari laporan penelitian tesis Program Pasca Sarjana
Universitas Negeri Yogyakarta, tahun 2009. Ucapan terimakasih disampaikan kepada Ibu Dr. Sufriati Tanjung (Pembimbing), Tim Penguji, Bapak/Ibu Dosen Prodi Linguistik Terapan, dan seluruh staff dan karyawan PPS UNY.

\section{DAFTAR PUSTAKA}

Alland, Keith \& Burridge, Kate. (1991). Euphemism and Dysphemism. Language Used As Shield and Weapon. Oxford: Oxford University Press.

Auswärtiges Amt. (2007). Fakta Mengenai Jerman. Edisi Bahasa Indonesia. Jakarta: Katalis.

Glück, Helmut. (1993). Lexikon Sprache. Stuttgart: Verlag J. B. Metzler.

Wijana, I Dewa Putu \& Muhammad Rohmadi. (2008). Semantik, Teori dan Analisis. Surakarta: Yuma Pustaka.

Keraf, Gorys. (2007). Diksi dan Gaya Bahasa (Edisi yang Diperbarui). Jakarta: Gramedia Pustaka Utama.

Schmidt, Elke. (11 Januari 2001). Euphemismus und Tod. http://www. sw2.euv-frankfurt-o.de/VirtuLearn/ hs.winter00/hs.kuolema/Seiten/programmseiten/euphemismen. html. (Diunduh 3 Mei 2008)

Wardhaugh, Ronald. (1990). An Introduction to Sociolinguistics. Massachussets: Basil Blackwell.

Zöllner, Nicole. (1997). Der Euphemismus im Alltäglichen und Politischen Sprachgebrauch des Englischen. Frankfurt am Main: Peter Lang $\mathrm{GmbH}$. 